\title{
Study of a-C:H thin films grown by PIII in different times for mechanical and Tribological applications
}

\section{Estudo de filmes finos de a-C:H crescidos por IIIP in differentes tempos para aplicações mecânicas e tribológicas}

Péricles Lopes Sant'Ana', Lucia Vieira dos Santos², Tiago Fiorini Silva ${ }^{3}$, Ronaldo Jr. dos Santos ${ }^{1}$, Jose Roberto Ribeiro Bortoleto ${ }^{1}$ Nilson Cristino da Cruz ${ }^{1}$, Elidiane Cipriano Rangel ${ }^{1}$, Steven Frederick Durrant ${ }^{1}$

\begin{abstract}
A Steel alloy (16MnCr5) used for automotive applications (engine components) was chosen as substrate to be covered by DLC films deposited by Plasma Immersion Ion Implantation. This kind of recovery is useful for improve its mechanical and tribological applications, more specific to increase surface hardness and to reduce the friction coefficient $(\mu)$. After polished and ultrasonicated, $16 \mathrm{MnCr} 5$ substrates were submitted to PIIID procedures for $100 \mathrm{~W}$ of radiofrequency power, from atmospheres supplied with $80 \%$ of methane and $20 \%$ of argon, keeping the work pressure fixed to 5.5Pascal.Four differentdepositiontimeswaschosenbeing of(1800s,

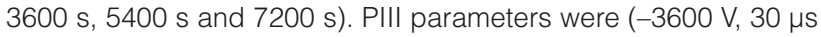
and $300 \mathrm{~Hz}$ ). It was investigated the effect of DLC properties over the substrates using Raman Spectroscopy (for Hydrogen content and microstructure analysis), Ultra Micro-Tribometer (for friction coefficient: $\mu$ ) and Nanoindentation (hardness).
\end{abstract}

Keywords: PIII\&D, DLC, 16MnCr5, Raman, Friction coefficient, hardness.

\section{RESUMO}

Uma liga de aço (16MnCr5) utilizada para aplicações automotivas (componentes de motores) foi escolhida como substrato para ser recoberta por filmes finos de DLC depositados por Implantação lônica por Imersão em Plasmas. Este tipo de recobrimento é útil para melhorar suas aplicações mecânicas e tribológicas, mais especificamente, para aumentar a dureza superficial e reduzir o coefficente de atrito $(\mu)$. Depois de polidas e limpadas em banho ultrasônico, substratos de $16 \mathrm{MnCr} 5$ foram submetidos ao procedimentos IIDIP por $100 \mathrm{~W}$ de potência da radiofrequência, em atmosferas contidas com $80 \%$ de metano e $20 \%$ de argônio, mantendo a pressão de trabalho fixa em 5,5 Pascal. Quatro diferentes tempos de deposição foram escolhidos sendo (1800 s, 3600 s, 5400 s e 7200 s). O parâmetros da IIIP foram (-3600 V, 30 us e $300 \mathrm{~Hz}$ ). Foi investigado o efeito das propriedades do DLC sobre os substrates usando Espectroscopia Raman (para contagem de Hydrogênio e análise microestrutural), Ultra microtribometria (para o coeficiente de fricção: $\mu$ ) e Nanoindentação (para análise da dureza).

Palavras-chave: PIII\&D, DLC, 16MnCr5, Raman, Coeficiente de fricção, dureza.

IUniversidade Estadual Paulista Julio de Mesquita Filho - Laboratório Tecnológico de Plamas - Sorocaba (SP) - Brazil

¿Universidade do Vale do Paraíba - Laboratório de Nanotecnologia e Processos a Plasmas - São José dos Campos (SP) - Brazil

${ }^{3}$ Universiddae de São Paulo - Laboratório de Análise de Materiais por Feixes lônicos- São Paulo (SP) - Brazil

Correspondence author: Péricles Lopes Sant'Ana - Universidade Estadual Paulista Julio de Mesquita Filho - Laboratório Tecnológico de Plamas - Av. Três de

Março 511, Alto da Boa Vista - CEP 18 087-180 - Sorocaba (SP) - Brazil

Email: drsantanap|@gmail.com

Received: 10/04/2016 Approved: 07/06/2017 


\section{INTRODUCTION}

The current trend in the automotive industry is to adopt designs, materials and surface treatments that lead to the development of more efficient engines with low friction, improved wear and reduced fuel consumption ${ }^{(1)}$. This can be achieved by methods that, employs specialized coatings (DLC's) which minimize the friction and wear on interacting components in both dry and lubricated contacts. Ofune M. et $\mathrm{al}^{(2)}$ have showed that $16 \mathrm{MnCr} 5$ alloy presented tribological results when it was recovered by DLC films. Nowadays, wear and friction coefficient conditions have been studied with large interest in the scientific community and industry ${ }^{(3)}$. Advances allow the deposition of coatings, as diamond-like carbon (DLC), with higher deposition rates, hardness, adhesion to metallic substrates, wear resistance and low friction coefficient ${ }^{(3)}$ and Diamond-Like Carbon ${ }^{(4)}$ is an amorphous carbon with significant fraction of C-C $\mathrm{sp}^{3}$ bonds. Several deposition methods have been developed in order to obtain a-C:H films with higher proportions of carbon atoms in $\mathrm{sp}^{3}$ hybridization ${ }^{(5)}$. Hydrogenated amorphous carbon films have found many applications due to association of properties such as high density, hardness, chemical inertness and smoothness ${ }^{(6)}$. In general way they are prepared via plasma techniques including all the CVD and PVD approaches. The deposited material may be tailored from soft polymeric to hard inorganic, depending on system parameters such as the monomers, comonomers, and their flow rates, the power applied to the discharge, deposition time, etc ${ }^{(7)}$. In this context, Plasma Immersion Ion Implantation \& Deposition (PIIID) is an especially interesting tool for the preparation of such films since it enables to control the energy deposited in the growing layer through ionic impacts. In this approach, the samples are immersed directly in plasma excited from organic compound pure or mixed to other gases while high voltage negative pulses are applied to the sample holder ${ }^{(8)}$. The energy transferred to the matter via ionic and electronic collisions, are suitable for the properties of the samples, recovered, including the type of microstructure formed in the a-C:H films. For different deposition times, it is possible to grow films in different thickness, which for itself, has influence on the timelife of these materials. In this work PIIID was used to grow a-C:H films over the surface of $16 \mathrm{MnCr} 5$ substrates, since this kind of recover over alloy steels usually improves the surface hardness and reduce its friction coefficient. It's in agreement with the automotive industry whereas; engine components may have its performance extended, owing to DLC recover on to this $16 \mathrm{MnCr} 5$ alloy steel, in order to resist against shear stress. Hence, microstructure of these films was investigated. Carbon forms a great variety of crystalline and disordered structures because it is able to exist in three hybridizations, $\mathrm{sp}^{3}, \mathrm{sp}^{2}$ and $\mathrm{sp}^{1(9)}$. In the $\mathrm{sp}^{3}$ configuration, as in diamond, carbon atoms four valence electrons are each assigned to a tetrahedrally directed $\mathrm{sp}^{3}$ orbital, which makes a strong $\sigma$ bond to an adjacent atom. In the three-fold $\mathrm{sp}^{2}$ coordinated configuration as in graphite, three of the four valence electrons enter trigonally directed $\mathrm{sp}^{2}$ orbitals, which form $\sigma$ bonds in a plane. The fourth electron of the $\mathrm{sp}^{2}$ atom lies in a $\mathrm{p} \pi$ orbital, which lies normal to the $\sigma$ bonding plane. This $\pi$ orbital forms a weaker $\pi$ bond with a $\pi$ orbital on one or more neighboring atoms. In the $\mathrm{sp}^{1}$ configuration, two of the four valence electrons enter $\sigma$ orbitals, each forming a $\sigma$ bond directed along $\pm \mathrm{x}$-axis, and the other two electrons enter $\mathrm{p} \pi$ orbitals in the $\mathrm{y}$ and $\mathrm{z}$ directions. Our results point out that, microstructure generated in the films deposited here is concerned to the DLC arranged in an amorphous carbons alloys, containing considerable hydrogen in (\%), that is possible to be an a-C:H or DLCH. According literature ${ }^{(10)}$, they are hard materials, containing about $40 \%$ of $\mathrm{sp}^{3}$ sites, $30-40 \%$ of $\mathrm{H}$, and and 10-20 GPa of hardness.

\section{METHODS}

Glass plates $\left(\sim 50 \mathrm{~mm}^{2}\right)$ and polished $16 \mathrm{MnCr} 5$ steel plaques $\left(\sim 50 \mathrm{~mm}^{2}\right)$ were employed as substrates for film deposition. Substrates were initially cleaned in ultrasonic (Cristofoli USC 3881 ) baths, then, $16 \mathrm{MnCr} 5$ steel substrates, polished in $3 \mu \mathrm{m}$ alumina grain, were cleaned in deionized water and alcohol baths. The cleaned substrates were positioned at the sample holder of a capacitive coupled plasma system, fully described in a previous work $^{(11)}$. The system was then, pumped picked up as Table 1 , according procedure developed by Oliveira ${ }^{(12)}$.

Profilometry was used to measure the thickness and roughness of the films. The equipment was a Dektak 150 (Veeco Company), scanning $500 \mu \mathrm{m}$ of distance in a frequency of $200 \mathrm{~Hz}$ using silicon tip. The micro-structure of the films was investigated by Raman Spectroscopy in a Renishaw S 2000 using an argon laser $(514.5 \mathrm{~nm})$. Spectra were acquired directly from samples prepared on steel $16 \mathrm{MnCr} 5$ in the wave number region 800 to $2000 \mathrm{~cm}^{-1}$. Hardness of the films was evaluated using the nanoindentation data acquired in a Hysitron Triboindenter. A multiple step load function presenting maximum and minimum loads of 100 and $1.000 \mu \mathrm{N}$, respectively were applied to a diamond Berkovich tip, providing hardness results for ten different depths. The load application and removal rates were $1 \mathrm{~s}$ and $1 \mathrm{~s}$, respectively, while dwell time was of $1 \mathrm{~s}$ for all the tests. The friction coefficients

Table 1: Parameters of a-C:H films deposition and plasma system conditions.

\begin{tabular}{|c|c|}
\hline Substrate & Steel Alloy $16 \mathrm{MnCr} 5$ \\
\hline Gas system & $\mathrm{CH}_{4} / \mathrm{Ar}$ \\
\hline Methane proportion & $80 \%$ \\
\hline Argon proportion & $20 \%$ \\
\hline Bias Voltage & $-3600 \mathrm{~V}$ \\
\hline Frequency & $300 \mathrm{~Hz}$ \\
\hline Pulse time & $30 \mu \mathrm{s}$ \\
\hline Work pressure & $5.5 \mathrm{~Pa}$ \\
\hline Deposition times & $1800,3600,5400$ and $7200 \mathrm{~s}$ \\
\hline RF Power & $100 \mathrm{~W}$ \\
\hline
\end{tabular}


was determined using ball-on plaque technique with Tribometer Setter - UMT (ultra microtribometer), at $\left(20 \pm 1^{\circ} \mathrm{C}\right)$ It was used the reciprocal linear module with a displacement of $10 \mathrm{~mm}$, a steel AISI 4040 ball of $4 \mathrm{~mm}$ in diameter, a constant force of $2 \mathrm{~N}$ and an average speed of $10 \mathrm{~mm} / \mathrm{s}$ for $300 \mathrm{~s}$.

\section{RESULTS}

\section{Thickness and Roughness}

Table 2 reveals the increase of thickness of the films when the samples were submitted to higher times of deposition. And the roughness where quite similar for all films excepted to the film deposited for the highest time (7200 s), that presented lower roughness.

According to the work done by Salvatori et al. ${ }^{(13)}$ at the beginning of the film deposition tends to increase the roughness became greater than the initial, due to deposition occurs quickly on the peaks than in the valleys. While increasing film thickness, the surface roughness decreases due to filling of the valleys generated by lateral growth surface ${ }^{(14)}$. During the glow discharge in the reactor, some processes begins to appear, such electrons collisions and ion bombardment. The fragmentation of the organic molecule under the plasma environment, leads to create low energy radicals that promptly react with radicals on the solid surfaces. Hydrocarbon gas such as methane is ionized in plasma, resulting in Hydrogen ions. They trend to create covalent bonds with $\mathrm{C}^{+}$ions. Furthermore, charged species formed in the plasma phase $\left(\mathrm{CH}^{+}, \mathrm{CH}_{2}^{+}\right.$and $\left.\mathrm{CH}_{3}^{+}\right)$; bombard the growing layer due to the polarization of the sample holder. Moreover, in organic materials, deposition of energy through ionic collisions induces, amongst other effects, bond rupture with emission of chemical species ${ }^{(15)}$. As hydrogen constitutes lateral or terminal groups in such materials it is very prone to be emitted upon bombardment, generating dangling bonds ${ }^{(16)}$. As these species are extremely unstable, they tend to be consumed through structural organization by crosslinking and carbon bond insaturation. As long as the substrates were fixed in the reactor during the deposition, then the recombination rate tends to increase resulting in lower defect concentrations, that is, in a better organized structure, but even, active sites still remain in the solid structure. Hence, species as $\mathrm{O}$ and $\mathrm{N}$ are expected in the structure of plasma deposited materials since residual radicals are incorporated in the structure during deposition, promoting

Table 2: Results of thickness and roughness of the films grown in four different treatment (deposition) times.

\begin{tabular}{|c|c|c|c|}
\hline Sample & $\begin{array}{c}\text { Deposition } \\
\text { time (s) }\end{array}$ & $\begin{array}{c}\text { Thickness } \\
(\mathbf{n m})\end{array}$ & $\begin{array}{c}\text { Roughness } \\
(\mathbf{n m})\end{array}$ \\
\hline I & 1800 & 53 & 10 \\
\hline II & 3600 & 190 & 10 \\
III & 5400 & 285 & 11 \\
\hline IV & 7200 & 390 & 5 \\
\hline
\end{tabular}

reactions with water vapor and atmospheric oxygen when the samples are exposed to atmosphere, in order to minimize the dangling bonds $\mathrm{s}^{(17)}$. The bonding in a:C-H can be described as follows. The $\mathrm{C} \mathrm{sp}{ }^{3}$ sites form a continuous network of $\mathrm{C}-\mathrm{C}$ bonds. Most $\mathrm{sp}^{3}$ sites are bonded to one or more hydrogens. A large part of the $\mathrm{sp}^{3}$ bonding in a-C:H is due to saturation of bonding hydrogens. The $\mathrm{sp}^{2}$ sites form small clusters in this matrix. In soft a-C:H the clusters tend to be olefin and do not give a Raman D peak. ${ }^{(18)}$. When those films are deposited at high bias, the $\mathrm{sp}^{2}$ clusters become larger and increasingly aromatic and so give rise to the observed D peak. The G peak position saturates at $1600 \mathrm{~cm}^{-1}$ at high photon energies for high bias samples, while it continues above $1600 \mathrm{~cm}^{-1}$ for polymeric a-C:H. So, Raman analysis is important to evaluate the microstructure of the films, and then, may be possible to understand the hardness values and friction coefficient of the films.

\section{Raman analysis}

Figure 1 shows the Raman spectra in the range of wavenumber: $800 \mathrm{~cm}^{-1}$ region for films grown in different times. All films presented the peak positioned next to $1540 \mathrm{~cm}^{-1}$ of wavenumber, typical of a-C:H films according Robertson ${ }^{(19)}$.

The Raman spectra exhibit asymmetric $\mathrm{G}$ band peak located at $1542 \mathrm{~cm}^{-1}$. This value is generally observed in the hydrogenated amorphous carbon type film (a-C:H) ${ }^{(20)}$, which typically exhibit high hardness, high density and carbon content of up to $20 \%$ C styling $(\mathrm{GLCH})$ or $20 \%$ at $40 \%$ carbon named $(\mathrm{DLCH})^{(20)}$. As $\mathrm{sp}^{3}$ hybridization and increases the amount of unordered connections, there is a shift of the $\mathrm{G}$ band to the a little bit to left, corresponding to movies closer to the diamond structures. Moreover, when the position of the $G$ band shifts to the right, it means there is an increased formation of carbon clusters. Other information that may be obtained from Raman spectra is the percentage of hydrogen in the film according to the method proposed in the literature, based on the determination of the spectrum baseline Raman tilt that appears due to the photoluminescence of $\mathrm{H}$ using

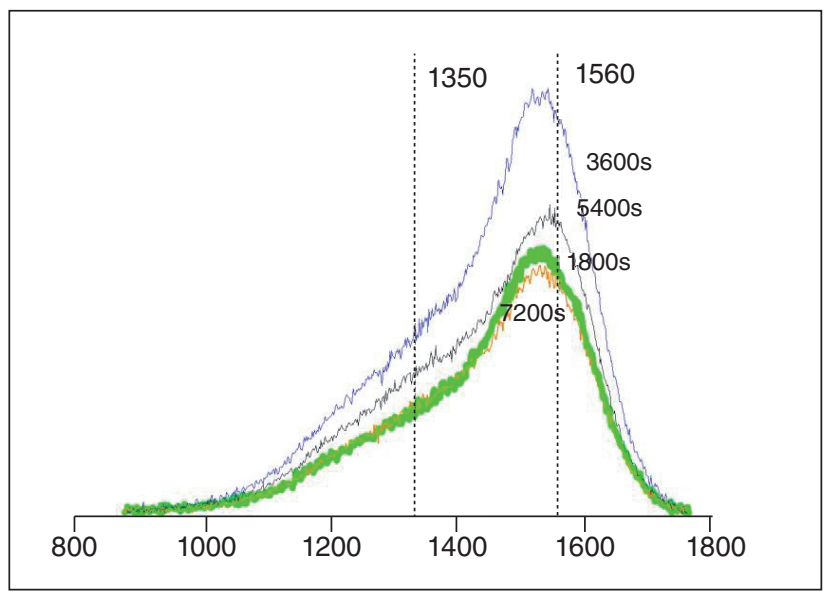

Figure 1: Raman Spectra of DLC films, as function of the deposition times $(1800,3600,5400$ and 7200 s). (Intensity u.a as funcion of wavenumber in $\mathrm{cm}^{-1}$ ). 
$514 \mathrm{~nm}$ lasers. Figure 2 gives additional information, and $\mathrm{G}$ position reveals the amorphization trajectory

The amorphization trajectory can previous how much sp3 sites can be the films are composed. Following the method proposed by Ferrari and Robertson ${ }^{(21)}$, the spectra were deconvoluted into two Gaussians, allowing to evaluate the band peak position (G position), the $\mathrm{I}(\mathrm{D}) / \mathrm{I}(\mathrm{G})$ intensity ratio and the full width at half maximum (FWHM) for four different points (deposition times). $\mathrm{I}(\mathrm{D}) / \mathrm{I}(\mathrm{G})$ assumes values between 0.52 and 0.80 . Associating at the beginning of stage 3 (three model stage) ${ }^{(19)}$, such considerations with the prevision of moderate contents of $\mathrm{H}(<45 \%)$, and $20 \%$ of sp3 sites films investigated here can be classified as a-C:H instead of polymer-like carbon. It is known that, if $\mathrm{I}(\mathrm{D}) / \mathrm{I}(\mathrm{G})$ results in low values, that is, if is negligible (next to 0 ) the $\mathrm{sp}^{2}$ phase is mainly organized in chains. On the other hand, high $\mathrm{I}(\mathrm{D}) / \mathrm{I}(\mathrm{G})$ values suggest that $\mathrm{sp}^{2}$ phase mainly in rings. In this case, the $\pi$ bonds are not fully delocalized on the rings. The low variation in $I(D) / I(G)$ while increasing methane proportion indicates that microstructure, including graphite grain size, as well as $\mathrm{H}$ proportion (22) are just slightly affected by such a parameter. Analyzing the G band position data (Fig.1), it is observed no dispersion in the $\mathrm{G}$ band, but only a slightly shift to lower wavenumbers next to $\left(1542 \mathrm{~cm}^{-1}\right)$. This change, related to the enhancement in the proportion of $\mathrm{sp}^{3}$ sites in the film, is very possibly caused by increment in the $\mathrm{H}$ proportion. Then, the sample with the highest $\mathrm{sp}^{2}$ fraction is that prepared with $3600 \mathrm{~s}$ of deposition time. Since the G band width characterizes the

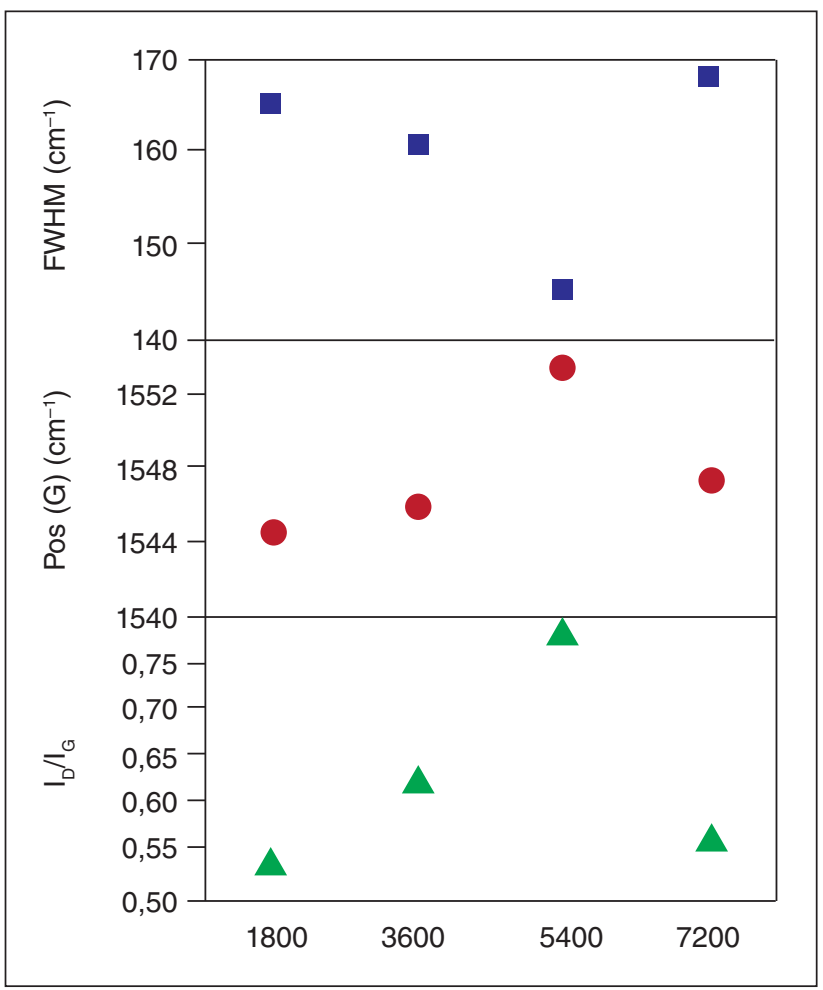

Figure 2: Raman Spectra deconvolution of a-C:H films, FWHM, Pos $(G)$ and $I_{D} / I_{G}$ as function of the deposition times (1800, 3600, 5400 and $7200 \mathrm{~s}$ ). disorder of the $\mathrm{D}$ band in the $\mathrm{sp}^{2}$ hybridization ${ }^{(23)}$, In Figure 2, also agrees with an elevation in the proportion of $\mathrm{sp}^{3}$ sites. The slender variations in the $G$ band position, band width and ID/IG ratio, may be a consequence of the predominant effect of the ion bombardment on the deposition kinetics. Possibly, stronger changes could have been detected if no ion bombardment was provided. About Pos (G) intensity, there is no significant factor to increase topological disorder if the ranged from 1542 to $1546 \mathrm{~cm}^{-1}$ is normal in the visible Raman excitation. Pos $(\mathrm{G})$ values ranged from 1542 and $1546 \mathrm{~cm}^{-1}$ indicates for high $\mathrm{H}$ content a character of the films between PLCH and DLCH, because it is a threshold on the curves that define the type of a-C:H films. If we link this analysis plus $\mathrm{G}$ peak disorder, it reinforces the idea we have from our films, once, for this type of films, presents topologically disordered, but the structural disorder is lowered. It is possible that, high $\mathrm{H}$ content concerned to the $\sigma$ bonds formation in order to minimize the free $\mathrm{H}$ energy. If we observe the film deposited to the $5400 \mathrm{~s}\left(\mathrm{t}_{\text {dep }}\right)$, it's possible to differ it because it's Pos $(\mathrm{G})$, is set to the wavenumber next to $1550 \mathrm{~cm}^{-1}$, that it means, the G peak at approximately $1550 \mathrm{~cm}^{-1}$ involves the in-plan bond

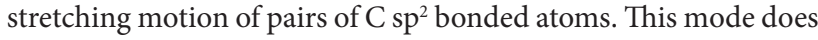
not require the presence of six-fold ring, and so it occurs at all $\mathrm{sp}^{2}$ sites, not only in the rings ${ }^{(24)}$. For the others conditions, the films seems to assume an a-C:H character as said before and confirmed by ${ }^{(20)}$ the work well analyzed by Schrader, using Infrared analysis to supply the microstructure information for carbon amorphous films.

\section{Friction coefficient}

Figure 3 shows the friction coefficient $(\mu)$, of the thin films ( $\mathrm{Y}$ axis) as a function of the sliding time (X axis), analyzing four different conditions (deposition times).

It is possible that an increase in the width of the tracks corresponding to an increase of the friction coefficient for the synthesized films with 3600 s, 5400 to 7200 are not occur with the film deposited under 1800s, suggesting a more efficient friction conditions. The behavior, $\mu$, in the sample which received the film deposited with a time 1800 s, where it is observed that the $\mu$ value starts at 0.2 and remained constant until the end of test $300 \mathrm{~s}$ without breaking the film. The initial value of 0.18 for film, $\mu$ deployed 3600s had an increase to a level of 0.4 to $70 \mathrm{~s}$ where the rupture of the film and the interaction of the tribometer coefficient measurement between the ball and the substrate; where it remained until the end of the test $300 \mathrm{~s}$. The behavior $\mu$ in the sample which received the deposited film 5400 with concentrations is observed that the value of $\mu$ starts at $0.2 \mathrm{~s}$ and holds up to 260 from where this reaches 0.3 until the end of test. The initial value of $0.18, \mu$ continuously maintain with $7200 \mathrm{~s}$ deployment time up to $150 \mathrm{~s}$ where from this point suffers a steady increase to the level of 0.35 reaching the end of test at $300 \mathrm{~s}$. In general, friction between surfaces in contact is affected by a variety of factors, however, it is controlled mainly by the formation and breaking of chemical 
bonds at the interface between the moving parts ${ }^{(25)}$. Saturation of the dangling bonds by atomic hydrogen or other adsorbates leads the friction coefficient of diamond to about $\mu=0.22$ and, atomic hydrogen ${ }^{(26)}$ acts as lubricants also for graphite and improve its wear and lubricating behavior. Since, Enke et $\mathrm{al}^{(27)}$ first reported in 1980 that, DLC from using a C source has low friction coefficients reinforcing its use as a lubricant, being in the air
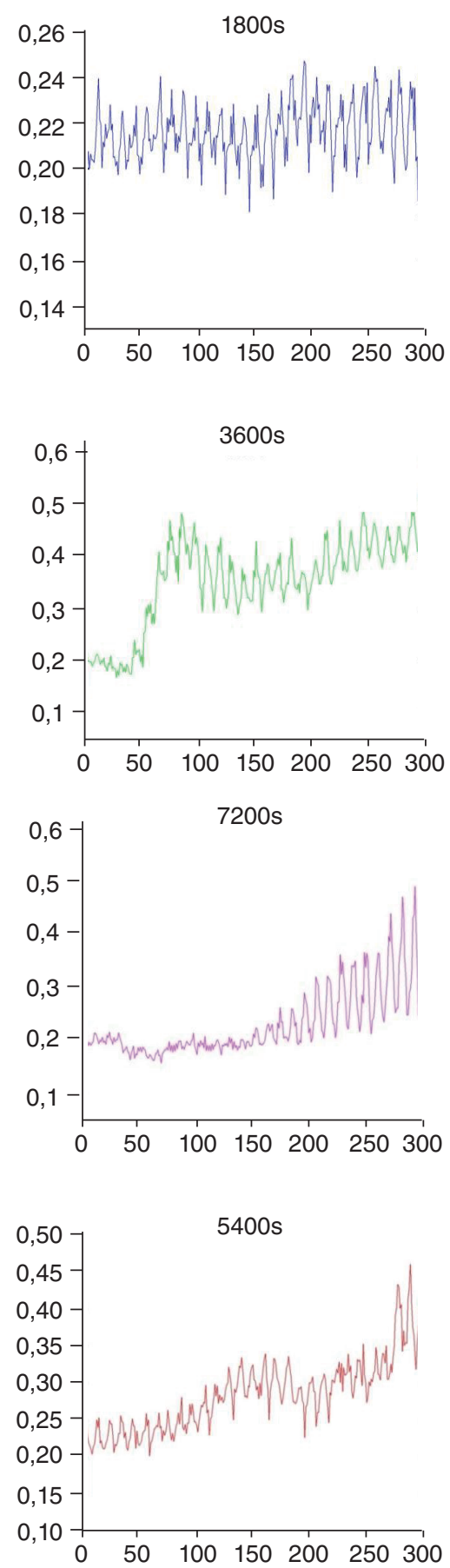

Figure 3: Friction coefficient $\mu$, of the films obtained as function of sliding time, in 4 samples, containing DLC films grown over the four different deposition times (1800, 3600, 5400 and $7200 \mathrm{~s})$. $0.10<\mu<0.40$. This is consistent with the results presented here. The friction properties of DLC's have reviewed recently by Grill ${ }^{(28,29)}$, Donnet ${ }^{(30)}$ and Gangopadhyay ${ }^{(31)}$. Erdemir et al ${ }^{(32,33)}$ have found that the friction coefficient on a-C:H from methane having the lowest $\mu$, being the opposite of a-C:H films from acetylene which presents the largest $\mu$.The large spread of values can be understood in terms of deposition system. In general, low values of these coefficients can be attributed to low shear strength of the transfer layer ${ }^{(34)}$. It is a consistent explanation with Raman analysis, which the layer has a disordered graphite structure, revealing evidence of amorphization of a-C:H films in the wear track. If the hydrogen is removed from hydrogenated DLC, the dangling bonds formed cause strong interactions between the surfaces in contact, resulting in a slope of friction coefficient as function of loss of hydrogen dry hydrogen ${ }^{(35)}$, similar to that reported for both graphite and diamond ${ }^{(36,37)}$.

\section{Hardness}

In Figure 4, hardness ( $\mathrm{Y}$ axis) of the samples is plotted as a function of the tip penetration depth in nanometers ( $\mathrm{X}$ axis). For the bare $16 \mathrm{MnCr} 5$, hardness keeps roughly constant around 2.0 GPa while for the samples containing the films, hardness progressively decreases with increasing depth. Considering shallower depths, where the influence of the substrate mechanical properties is reduced, it is possible to verify the influence of deposition times on the hardness of the a-C:H films. The best condition was the film deposited in $7200 \mathrm{~s}$, which hardness reached more than $20 \mathrm{GPa}$ ending to $15 \mathrm{GPa}$. Great hardness is typical for a-C:H films, confirmed by Raman analysis. Similar values were found for the films grown in another deposition times $\left(\mathrm{t}_{\mathrm{dep}}\right)$.

In order to minimize the influence of steel substrate on the hardness results, hardness values were determine at regions which correspond to less than $15 \%$ of the film thickness. The hydrogen

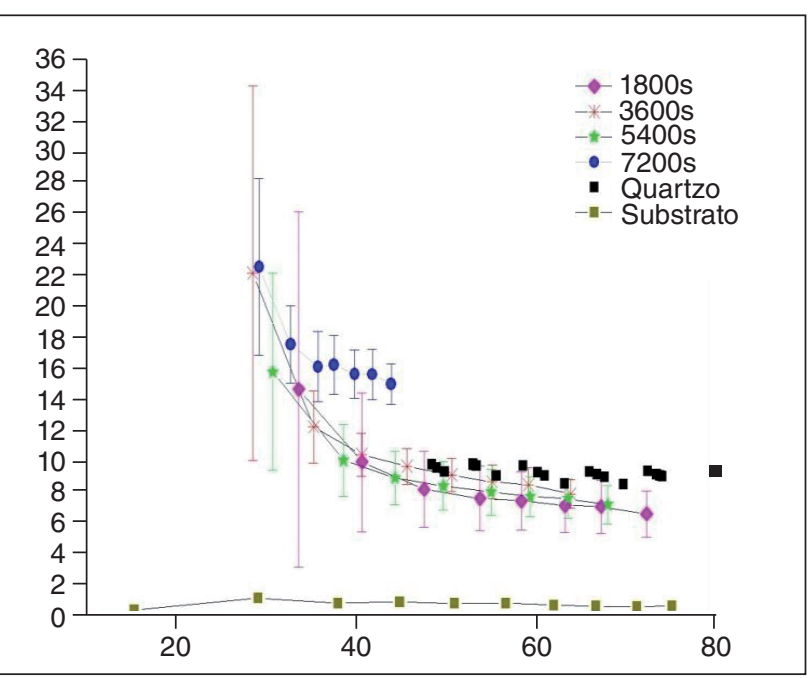

Figure 4: Hardness as function of depth of films, in 4 samples, containing DLC films, grown over the four different deposition times (1800, 3600, 5400 and 7200 s). 
tends to connect via $\sigma$ networks, $\mathrm{C}-\mathrm{H}$ bonds, which ultimately relieves stress and produces a softer polymer-like-carbon. Graphitization of microstructure can be responsible to decrease hardness ${ }^{(38)}$. In contrast, $\mathrm{sp}^{3}$ content is responsible to increase hardness when associated to $\mathrm{C}-\mathrm{C}$ bonds. For the films produced in this work, this combination is in agreement with a-C:H in the literature because of a non-extreme values founded that reveal good hardness $(10<\mathrm{H}<20 \mathrm{GPa})$, and good low friction coefficients at the same time. It's consistent when we confirm $\mathrm{sp}^{2}$ and $\mathrm{sp}^{3}$ sites for those films, characterizing the status of a-C:H films as observed by Tamor et al. ${ }^{(39)}$ to derive the fractions of the various $\mathrm{C}-\mathrm{H}$ configurations. In our case, aromatic rings formed in the $\mathrm{C}$ films are resistant against penetration, explaining the good hardness properties.

\section{CONCLUSIONS}

According microstructure analysis, friction coefficient, hardness, and hydrogen content $(\sim 40 \%$ of $\mathrm{H})$ obtained in this study demonstrated that coating can be classified as a-C:H, mixing $\mathrm{sp}^{3}$ sites and $\mathrm{sp}^{2}$ sites. The qualitative adherence of coatings was regular for all substrate surfaces revealing good adhesion. It was noted that, the coating deposited in 1800 showed the lower friction coefficient ( $\mu=0.2$ for a whole sliding time), and the film deposited in 7200 ( > thickness), presented higher hardness, both coatings represent the best combinations of characteristics as coatings to engine parts. In terms of microstructure, Raman analysis was consistent to reveals $\mathrm{G}$ position in $1542 \mathrm{~cm}^{-1}$ typical of a-C:H, and $1550 \mathrm{~cm}^{-1}$ implying in good evidence of stretching modes of carbon containing $\mathrm{sp}^{2}$ sites, hence the a-C:H character is useful to the explanation of the good behavior of the engine parts recovered by this thin film, and even, is pleasure to understand or predict its tribological behavior.

\section{ACKNOWLEDGEMENTS}

The authors are grateful to Brazilian agencies FAPESP, CAPES and CNPq by financial support.

\section{REFERENCES}

1. T. S. EYRE AND B. CRAWLEY, "Camshaft and cam follower materials," Tribology International, vol.13, pp. 147-152, 1980. https://doi.org/10.1016/0301-679X(80)90029-8

2. OFUNE M., YANG L., MORINA A., NEVILLE A. DLC coatings for cam follower applications: The role of the surface on tribochemical reactions, friction and wear. Proceedings of Malaysian International Tribology Conference 2015, pp. 298-299, November 2015.

3. A. ERDEMIR. Proc. Inst. Mech. Eng. Tribol., 216 (2002), pp. 387400.https://doi.org/10.1243/135065002762355316

4. V.J. TRAVA-AIROLDI, L.F. BONETTI, G. CAPOTE, J.A. FERNANDES, E. BLANDO, R. HÜBLER, P.A. RADI, L.V. SANTOS,
E.J. CORAT. Thin Solid Films, 516 (2007), pp. 272-276.https://doi. org/10.1016/j.tsf.2007.06.100

5. J. ROBERTSON, Mater. Sci. Eng. R 37 (2002) 129. https://doi. org/10.1016/S0927-796X(02)00005-0

6. R. D. MANSANO, M. MASSI, A. P. MOUSINHO, L. S. ZAMBOM, L. G. NETO, Diamond Relat. Mater. 12 (2003) 749. https://doi. org/10.1016/S0925-9635(02)00270-4

7. W. ENSINGER, Correlations between process parameters and film properties of diamondlike carbon films formed by hydrocarbon plasma immersion ion implantation, Surface and Coatings Technology 203 (2009) 2721-2726. https://doi.org/10.1016/j.surfcoat.2009.02.101

8. J.R. CONRAD, IN A. ANDERS (Ed.), Handbook Plasma Immersion Ion Implantation and Deposition, first ed, John Wiley and Sons, New York, 2000. P.1.

9. J. ROBERTSON / Materials Science and Engineering R 37 (2002) $129^{-1} 30$.

10. P. KOIDL, C. WAGNER, B. DISCHLER, J. Wagner, M. Ramsteiner, Mater. Sci. Forum 52 (1990) p.41. https://doi.org/10.4028/www. scientific.net/MSF.52-53.41

11. R.C.C. RANGEL et al. / Surface \& Coatings Technology 204 (2010) 3022-3028. https://doi.org/10.1016/j.surfcoat.2010.03.055

12. OLIVEIRA, L. C. Efeitos de tratamentos a plasma na limpeza e na reatividade de aços carbono, 2008, p.1-97.

13. SALVATORI, M. C.; MARTINS, D. R.; CATTANI, M. Surf. \& Coat. Technol. 2006

14. BARABASI, A. L.; STANLEY, H. E., Fractal concepts in surface growth, Cambridge University Press. 366 (1995) p. 151-152.

15. E.H. LEE, in: K. Mittal, M. Ghosh (Eds.), Polyimides: Fundamental Aspects and Technological Applications. Marcel Dekker, New York, 1996, cap.17

16. E.H. LEE, G.R. RAO, L.K. MANSUR. TRIP 47 (1996) p.229.

17. N. M. S. MARINS et al. / Surface \& Coating Technology 206 (2011) p.642. https://doi.org/10.1016/j.surfcoat.2011.06.058

18. J. ROBERTSON / Materials Science and Engineering R 37 (2002) p. 212

19. CASIRAGHI, F. C.; ROBERTSON, A.C.J. Physical Review. UK. 14 B 72, 2005.

20. SCHRADER, B. Infrared and Raman Spectroscopy. Methods and Applications; Ed.; VCH: New York, NY, 1995. 2301995 p137-159. https://doi.org/10.1002/9783527615438

21. A. C. FERRARI AND J. ROBERTSON, Phys Rev. B 64, 075414 (2001). https://doi.org/10.1103/PhysRevB.64.075414

22. FERRARI, A. C. Determination of bonding in diomond-like carbon by Raman Spectroscopy. Diamond and Related Materials. v. 11, p. 1053-1061, 2002. https://doi.org/10.1016/S0925-9635(01)00730-0

23. FERRARI A. C., ROBERTSON J. Interpretation of Raman spectra of disordered and amorphous carbon. Physics Review B, v. 61, m 20, p. $14095^{-1} 4107,2000$.

24. A.C FERRARI, J ROBERTSON. Phys. Rev. B, 61 (2000), p. 14095

25. E. RABINOWICZ, Friction and Wear of Materials, Wiley, New York, 1965.

26. V. I. MERKULOV, J. S. LANNIN, C. H. MUNRO, S. A. ASHER, V. S VEERASAMY, AND W. I. MILNE, Phys. Rev. Lett. 78, 48691997. https://doi.org/10.1103/PhysRevLett.78.4869 
27. K. ENKE, H. DIMIGEN, H. HUBSCH. Appl. Phys. Lett. USA vol. 36 (1980) p.291. https://doi.org/10.1063/1.91465

28. A. GRILL, Wear 168, (1193) 143.

29. A. GRILL, Surf. Coatings Technol. 94 (1997) 507. https://doi. org/10.1016/S0257-8972(97)00458-1

30. C. DONNET, Surf. Coatings Technol. 100 (1998) 180. https://doi. org/10.1016/S0257-8972(97)00611-7

31. A. GANGOPADHYAY, Tribol. Lett. 5 (1998) 25. https://doi. org/10.1023/A:1019152515982

32. A. ERDEMIR, O. L. ERYILMAZ, I. B. NILUFER, G. R. FENSKE, Diamond Rel. Mater 9 (2000) 632. https://doi.org/10.1016/S09259635(99)00361-1

33. A. ERDEMIR, O. L. ERYILMAZ, G. R. FENSKE, J. Vac. Sci. Technol. A 18 (2000) 1987. https://doi.org/10.1116/1.582459
34. C. DONNET, M. BERLIN, J.C. AUGE, J.M. MARTIN, A. GRILL, V. PATEL. Surf. Coat. Technol. Switzerland vol.68-69 (1994) p.626. https://doi.org/10.1016/0257-8972(94)90228-3

35. R. Memming, H. J. TOLLE, P.E. WIERENGA. Thin Solid Films (Switzerland) vol. 143 (1986) p.31. https://doi.org/10.1016/00406090(86)90144-6

36. H. ZAIDI, A. MEZIN, M. NIVOIT, J. LEPAGE. Appl. Surf. Sci (Netherlands) vol. 40 (1989) p.103. https://doi.org/10.1016/01694332(89)90164-5

37. L. P. HAYWARD. Suf. Coat. Technol. (Switzerland) vol.49 (1991) p.554. https://doi.org/10.1016/0257-8972(91)90116-E

38. R. W. LAMBERTON, J. F. ZHAO, J.A. MCLAUGHLIN, P.D. MAGUIRE. Diam. Relat. Mater. (Switzerland) vol.7 (1998) p.1054. https://doi.org/10.1016/S0925-9635(98)00153-8

39. M.A. TAMO, W.C. VASSELL, K. R. CARDUNER. Appl. Phys. Lett. USA vol.58 (1991) p.592. https://doi.org/10.1063/1.104597 